\title{
Countable or Uncountable? That is the Question - Lexicographic Solutions to Nominal Countability in Learner's Dictionaries for Production Purposes
}

\author{
Mei Xue, Centre for Lexicography, Aarhus School of Business, Aarhus
} University, Aarhus, Denmark (meix@asb.dk)

\begin{abstract}
Nominal countability is problematic for foreign learners in production-oriented activities, especially for those whose native language does not have the corresponding function systems. In contrast to foreign learners' great difficulties with nominal numbers in foreign text production as shown in extensive linguistic research, there is a scarcity of lexicographic research on assisting foreign learners with their difficulties in this respect. Prompted by the great discrepancy between foreign learners' needs for lexicographic assistance and the relative indifference concerning this in lexicographic research, this study attempts to explore to what extent the lexicographic data in connection with nominal countability and their presentation in present learner's dictionaries can help foreign learners in foreign text production. This study will offer some constructive lexicographic solutions to the problems incurred by foreign learners' misconceptions of nominal countability in foreign text production.
\end{abstract}

Keywords: CHINESE EFL LEARNERS, CHINESE LEARNERS' DIFFICULTIES, DATA ACCESSIBILITY, DATA PRESENTATION, FOREIGN TEXT PRODUCTION, LEXICOGRAPHIC INFORMATION NEEDS, INFORMATION RETRIEVAL, LEARNER'S DICTIONARIES, LEXICOGRAPHIC SOLUTIONS, NOMINAL COUNTABILITY, PROFILE OF CHINESE LEARNERS

Opsomming: Telbaar of ontelbaar? Dit is die vraag - Leksikografiese oplossings vir naamwoordelike telbaarheid in aanleerderswoordeboeke vir produksiedoeleindes. Nominale telbaarheid is problematies vir vreemde aanleerders by produksiegerigte handelinge, veral vir hulle wie se moedertaal nie die ooreenstemmende funksiesisteme het nie. In teenstelling met vreemde aanleerders se groot moeilikhede met nominale getalle in vreemdeteksproduksie soos uit omvattende taalkundige navorsing blyk, is daar 'n skaarste aan leksikografiese navorsing wat vreemde aanleerders help met hul moeilikhede in hierdie opsig. Na aanleiding van die groot verskil tussen vreemde aanleerders se behoefte aan leksikografiese hulp en die relatiewe onbelangstellendheid hieroor in leksikografiese navorsing, probeer hierdie studie nagaan tot watter mate die leksikografiese data in verband met nominale telbaarheid en die aanbieding hiervan in huidige aanleerderswoordeboeke vreemde aanleerders in vreemdeteksproduksie kan help. Hierdie studie sal enkele konstruktiewe leksikografiese oplossings aanbied vir probleme ondervind as gevolg van vreemde aanleerders se wanopvattings oor nominale telbaarheid by vreemdeteksproduksie. 
Sleutelwoorde: SJINESE EVT-AANLEERDERS, MOEILIKHEDE VAN SJINESE AANLEERDERS, DATATOEGANKLIKHEID, DATA-AANBIEDING, VREEMDETEKSPRODUKSIE, LEKSIKOGRAFIESE INLIGTINGSBEHOEFTES, INLIGTINGSHERWINNING, AANLEERDERSWOORDEBOEKE, LEKSIKOGRAFIESE OPLOSSINGS, NOMINALE TELBAARHEID, PROFIEL VAN SJINESE AANLEERDERS

\section{Introduction}

Attention to the countability of nouns in learner's dictionaries can be traced to as early as 1938 in Palmer's Grammar of English Words. Later, Hornby et al. used the abbreviations $[\mathrm{C}]$ and $[\mathrm{U}]$ to indicate the nominal countability in their Idiomatic and Syntactic English Dictionary (Cowie 1999: 46). Present learner's dictionaries follow the practice of using the labels $[\mathrm{C}]$ and $[\mathrm{U}]$ as well as the further specifications like singular and plural to indicate the numeral aspects of a noun. Miller (2006: 435) seems to be overconfident of such a practice by stating that "the inclusion of countability in learner's dictionaries has provided successive generations of students with a ready-made tool to help them acquire one of the hardest grammatical features of the English language". The inclusion of information related to nominal countability in learner's dictionaries will assist foreign learners in certain situations, but it is doubtful whether the mere act of including such data will automatically be helpful. Even Miller's (2006: 439) own study shows that there is a very subtle "difference in increased correctness between the dictionary and non-dictionary users", but she attributes the causes of her findings to learners' "lack of familiarity with the dictionaries, and their reluctance to check every noun in the dictionary for countability".

The assumption can seemingly be made that the present lexicographic practice of indicating information in connection with nominal countability in learner's dictionaries is transparent enough for foreign learners to confront their difficulties in this respect. However, it is doubtful whether the information retrieval process is as transparent as promised considering the fact that foreign learners with different language and cultural backgrounds may have a different conceptual understanding of the numeral aspects of a noun, and therefore have different lexicographic information needs. Despite the occasional doubt expressed about the present lexicographic practice, so far little serious attention has been paid to discussing the possible lexicographic solutions to foreign learners' difficulties in connection with nominal countability in foreign language learning.

Hornby (1965: 109-110) earlier identified foreign learners' difficulties regarding the numeral aspects of nouns in English, such as singular, plural, countable and uncountable. To address foreign learners' misuse of articles caused by their misconception of countability, he proposes that "the dictionary must show, by the provision of examples, when these phrases with significant article omission are possible and what the omission of the article indicates". 
Later, Hausmann and Gorbahn (1989: 52) mention that contextual usage examples are needed for learners' correct application of the concept of countability of nouns, and point out that the mere marking of countability in the form of [C] and [U] without further explanations in some noun entries such as hair will confuse foreign learners engaged in production activities. But, as the aim of their study is to make a comprehensive comparison of two dictionaries (e.g. COBUILD and LDOCE II), the discussion about the lexicographic treatment of the countability of nouns is not pursued further. Discussing dictionary grammars, Andersen (2007: 121) proposes that the data related to nominal countability should be presented in a specific grammar part in view of the difficulty in indicating possible verb forms following collective nouns in an economical way or inventing economical codes to illustrate various determiners with nouns. However, this study is more concerned with the specific usage situation in which a noun is used, rather than the user situation giving rise to the varieties of usage situations in which a noun is involved when referring to the presentation of the data related to nominal countability.

In contrast to the scarcity of lexicographic research on nominal countability, extensive research in applied linguistics has revealed the evident difficulties foreign learners experience in production activities and the various types of errors incurred by the misconception of nominal countability, including the misuse of the English article system, the wrong use of quantifiers and premodifiers, the violation of subject-verb agreement, etc. (cf. Swan and Smith 1987; Sinclair 1991; Master 1997, 2002; Robertson 2000; Milton 2001; Chuang 2005). The asymmetry between foreign learners' practical difficulties caused by nominal countability in foreign language learning and the indifference shown in lexicographic research prompts this study to explore to what extent the present lexicographic practice of indicating nominal countability in learner's dictionaries can help foreign learners in foreign text production. It is followed by an attempt to propose some suggestions for future lexicographic practice. The profile of foreign learners as dictionary users shaped by their native language and social cultural contexts will be highlighted, as foreign language learning cannot take place in a vacuum.

This study consists of the following three stages. First, it identifies the semantic, syntactic as well as pragmatic difficulties in connection with nominal countability experienced by a specific group of learners in a specific user situation. It focuses on Chinese learners of English at college level in writing English under foreign language learning circumstances. Second, it examines the present lexicographic treatment of nominal countability in major learner's dictionaries in print as well as online formats. Some articles are analyzed to explore how to optimize appropriate lexicographic assistance with the countability concept sought by Chinese learners in English writing. Finally, suggestions are proposed and demonstrated in example articles for future lexicographic research and practice. As this study is limited to English learner's dictionaries, so reference to dictionaries in the following is to English learner's dictionaries only. 
2. Chinese learners' lexicographic information needs for nominal countability in foreign text production

Foreign learners seldom look for information about nominal countability in dictionaries to comprehend foreign texts except when the ambiguity in comprehension is caused by the numeral features of a noun or the numeral inflection of a noun which may prevent them from identifying the canonical word form. Unlike the primary pursuit of meaning in foreign text reception, production-oriented activities demand fluency as well as accuracy, so the word form regarding nominal countability becomes evident. The numeral features of a noun will decide the determiners or quantifiers preceding a noun as well as the verb forms following it. The significance of appropriately using a noun in syntactic environments may be interpreted at lexical, semantic, grammatical and pragmatic level. The difficulties of foreign learners in this respect have been observed in many studies. Chinese learners of English engaged in English writing are no exception. Normally dictionaries, unlike grammar books, will have been observed to address such difficult problems, because learner's dictionaries are generally assumed to provide a variety of specific information about individual words while grammar books mainly focus on general grammatical rules.

In addition, in Chinese learning culture, dictionaries are regarded as almost unchallenged authorities of knowledge. So, when Chinese learners are uncertain of the countability features of a noun which they intend to use, they may seek assistance from available dictionaries to assure themselves of the appropriate syntactic behaviour of a noun to achieve accuracy in cross-cultural communication. As the overriding function of learner's dictionaries is to satisfy learners' punctual information needs regarding foreign language learning (Tarp 2008: 137), it is therefore essential to identify Chinese learners' information needs for lexicographic assistance regarding nominal countability, and to discuss how to present the data relevant to nominal countability to cater for Chinese learners' lexicographic needs in writing English.

\subsection{The profile of Chinese learners}

A description of the profile of Chinese learners will shed some light on understanding their particular lexicographic information needs concerning nominal countability, because their specific needs for lexicographic assistance is greatly subject to their profile in foreign language learning situations. The profile of Chinese learners in this study can be described by the following parameters: their native language, their learning contexts, the didactics, and their world knowledge. Although learners at college level are normally assumed to be at intermediate level in the Chinese educational context regarding their English proficiency, they still resort to their native language (e.g. generally Mandarin Chinese) when they are impeded in formulating their ideas. Their world 
knowledge determined by their socio-cultural context tends to colour the concepts they attempt to express in their English writing.

To be more specific: This group of Chinese learners is normally at the age ranging from 17 to 20 . Upon reaching college-level education, they have usually been learning English in formal classroom context for 6-9 years or more. The concept of nominal countability and the relevant grammar is assumed to be taught consciously in class in the first year of junior middle school when most Chinese learners start their formal English learning. Although nominal countability is clearly stated as one of the important teaching and examining points in the English teaching syllabus administrated by the Chinese Ministry of Education, the interpretation and implementation of the teaching syllabus largely rest with individual English teachers. Therefore, when the uneven education resources distributed in the large geographic areas of China is considered, it is highly doubtful whether the teaching of English grammar is systematic regarding nominal countability, including articles, quantifiers, subject-verb agreement, etc.

\subsection{Chinese learners' difficulties}

Despite the tradition of emphasizing the learning of English vocabulary in Chinese education, the need to differentiate the countability of a noun in terms of the meaning used in specific contexts is not adequately taught. The plural meaning in Chinese is implicitly encoded in contexts while the countability of a noun in English will distinctively influence the syntactic environment. This difference between Chinese and English often causes Chinese learners to be unaware of the concept of nominal number in English, resulting in errors with regard to the form of the word in specific contexts. For instance, experience, punishment and difficulty are syntactically countable and uncountable depending on the meaning they take in specific contexts. Furthermore, the memorization, mainly the rote-learning strategy in Chinese education, demands much cognitive effort from Chinese learners, especially regarding irregular plural inflections or nominal variability. Consequently, Chinese learners commit many formal errors (Gui and Yang 2003; Chuang 2005: 26-27).

In short, Chinese learners at college level are aware of nominal countability and are assumed to be familiar with the basic grammatical rules regarding numeral inflections, article use, quantifiers, subject-verb agreement, etc. Their native language (e.g. generally Mandarin Chinese) and culture greatly influence their conceptual understanding of nominal countability. However, as shown in many studies (Chang 1987; Milton 2001; Gui and Yang 2003; Chuang 2005; Tang 2006), their skills in using such consciously-acquired knowledge actively are not at all promising. Despite the early input of nominal countability in English education, Chinese learners constantly show uncertainty regarding the concept of countability, and find it hard to identify whether a noun is countable or whether it takes countable or uncountable senses. 
There are various reasons for the great difficulties Chinese learners experience in their productive use of nominal countability. First of all, there are no corresponding function systems in Chinese, including numeral inflections, articles, subject-verb agreement, etc. The great divergence between Chinese and English language and culture demands Chinese learners consciously learning many of the grammatical features obligatory in English but absent from Chinese. Additionally, owing to the heterogeneity in languages and cultures, the conceptual understanding of the countability of the material world in Chinese is greatly different from English. Chinese learners therefore have to adjust their mappings about the lexical, semantic, syntactic and pragmatic features between the target foreign language (English) and their native language (generally Mandarin Chinese). Native speakers may be unaware of judging the countability of a noun, using articles or quantifiers intuitively, but foreign learners like Chinese have to memorize the corresponding grammar rules in this respect and use them consciously to maintain accuracy and fluency in their writing. For instance, luggage, information and furniture are uncountable in English, but countable in Chinese. So, it is common for Chinese learners to write two/many luggage(s)/information(s)/furniture(s) or to put an article a/an before these words.

Furthermore, there is no clear-cut distinction made between countable and uncountable nouns in grammar books (cf. Svensson 1998: 51-73). Some grammar books have become less definite in defining countability and plurality, blurring the boundaries between the countable and the uncountable according to contextual meanings (Tang 2006: 274). The variability in nominal countability also occurs as a result of social developments. Some traditionally uncountable nouns can be used as countable nouns acquiring new meanings in different disciplines, such as moneys in the business sense. The word mail is uncountable in traditional contexts, but a mail is appropriate when mail refers to the concept of an e-mail. On the other hand, grammar books and English teaching fall far short from covering the deviations with which foreign learners are confronted in their actual production activities.

As Svensson (1998: 13) states that "number is not only reflected in the nouns themselves, but also in verbs, modifiers and pro-forms", the misconception of nominal number may result in various errors in production activities. Common errors by Chinese learners related to nominal countability are the following: wrong inflection forms, misuse of the articles $a$ /an and the or no article before a noun, mixing countable with uncountable nouns, wrong word forms in contextual usage, and subject-verb disagreement especially involving collective nouns. Among these errors, those caused by the misuse of articles rank high in writing (Gui and Yang 2003; Chuang 2005). A frequency count (Sinclair 1991) indicates that in English the definite article the is the most common word and the indefinite article $a / a n$ is the fifth most common, so any difficulty with articles tend to be very conspicuous in foreign learners' production activities. The errors caused by the misuse of articles or quantifiers rarely lead 
to miscomprehension. However, they will affect the exactness highly valued in written work, as Master (1997: 216) points out: "[i]mperfect control [of using articles] may consciously or unconsciously, suggest imperfect knowledge, and if such an attitude is engendered in the mind of a professor grading a student's paper, that student's grade may suffer."

\subsection{Chinese learners' information needs}

When the profile of Chinese learners and their difficulties incurred by nominal countability is taken into consideration, Chinese learners expect to find the relevant information explicitly and explicatively presented in learner's dictionaries for their ready use in production activities. Therefore, it is significant for lexicographers to identify foreign learners' real information needs for lexicographic assistance covering nominal countability. Chinese learners' information needs concerning nominal countability can be rendered in the following specifications:

(a) the articles or quantifiers before a noun,

(b) the plural forms of the countable noun,

(c) the usage of a noun used both as countable and uncountable,

(d) the specific usage of the singular or plural form of a noun,

(e) the verb form following a noun, and

(f) the countability of neologisms.

These information needs are influenced by foreign learners' native language and culture because foreign learners with different language and cultural backgrounds may have general as well as specific difficulties regarding nominal countability. Nonetheless, learner's dictionaries as well-acknowledged reference tools in foreign language learning are expected to address these problems by presenting the necessary data as transparently as possible for the convenience of foreign learners. A closer look at current printed and online learner's dictionaries in the following sections is meant to examine to what extent present lexicographic practices achieve their claimed pedagogical functions of making provision for learners' information needs in foreign language learning.

\section{Problems with the present lexicographic practice with nominal count- ability}

In the process of searching for lexicographic assistance for communicative purposes, dictionary users normally experience two stages: access to the needed data and retrieval of the necessary information from the corresponding data. 
Thus, two essential questions are relevant to the presentation of the lexicographic data the target users need in their particular situations: is the required data easily identified and quickly accessed; and is the needed data comprehensible for the information retrieval with a minimum effort? Simply put, foreign learners may confront access-related and comprehension-related difficulties in the process of dictionary consultation when they turn to dictionaries for information related to nominal countability. An analysis of the present lexicographic practice will be illuminating.

The latest major English learner's dictionaries in print and in online format indicate nominal countability by labels [C] and [U]. The specifications like [singular], [plural], [often plural] [usually plural] and [U/C+ singular/plural verb] are supplemented in some cases. Abbreviations like [C], [U], [sing.], [pl.] are normally used, for reasons of space, in the latest printed dictionaries, such as Oxford Advanced Learner's Dictionary of Current English and Macmillan English Dictionary (henceforth OALD7 and MED2 respectively). Online dictionaries, free of space restraints, generally indicate such information unabbreviated. Usage examples are usually provided following the sense differentiation. To sum up: The data relevant to nominal countability are normally presented in the form of labels and specifications before definitions, and demonstrated in usage examples, regardless of the dictionary formats. As discussed above, this lexicographic practice has seldom been challenged. However, is such a lexicographic practice effective to address learner's difficulties related to nominal countability in production-oriented activities? In the following discussion, four articles education, effort, fish, and information are randomly taken from a printed dictionary, OALD7, and online dictionaries, such as Longman Dictionary of Contemporary English Online and Macmillan Dictionary Online (henceforth LDCEO and MDO respectively) for a close examination. In Chinese, the concepts education and effort are abstract and understood as uncountable, and the concepts fish and information as countable. In writing, the possible deviations Chinese learners make with regard to these four words could be: get education, receive good education, make (an/many) effort(s), a/many fish(es), an/many information(s).

\subsection{Absence of indicating articles or quantifiers used before a noun}

Labels [U] and [C] indicate the countability of a noun, but fail to provide explicit information for foreign learners' use of articles or quantifiers before the noun, especially for Chinese learners whose native language lacks the corresponding grammar function systems. Moreover, whether the article $a$ or an should be used before a countable noun depends on pronunciation, not spelling. It is even more difficult for Chinese learners to be aware of the use of no article or a definite article the. Therefore, they may insert articles when unnecessary, but omit articles when necessary. They have to consider which article is appropriate to be used before a noun even after having consulted dictionaries. 
Even the label [U] may not prevent Chinese learners from producing three/ many information(s) if they are also uncertain about quantifiers. To some extent, the labels [U] and [C] are testing learners' grammar knowledge rather than assisting them.

\subsection{Equivocal indication in the countability features of a noun}

Marking a noun as both countable and uncountable without further specification would confuse Chinese learners rather than assure them of the correct usage in production activities. For instance, effort is marked as countable and uncountable when it means "attempt" (e.g. LDCEO and MDO). Does this mean that make an/the effort/efforts and make effort are grammatically appropriate? In LDCEO all examples following this sense only show the countable features, ignoring the uncountable features, either intentionally or unintentionally. The treatment in MDO is almost similar except that the phrases make little/no effort are provided, but the plural form efforts is used in the example demonstrating the usage of the phrases. In contrast, in OALD7 effort is marked as countable when it means "attempt". Does this indicate to foreign learners that effort can be syntactically singular or plural when they intend to use it in the above-mentioned contexts? If so, the marking of countable and uncountable seems to be superfluous.

Moreover, the bracketed specifications like [often plural] and [usually plural] tend to be ambiguous, as there is always uncertainty about how to interpret the word "often" and "usually" in production situations. The targeted Chinese learners, still in the process of developing their foreign language literacy, are rather "passive" in using their knowledge about English, and expect explicit guidance from the dictionaries rather than information that demands further interpretation. The authoritative status dictionaries have in the Chinese learning culture just strengthens such expectations.

\subsection{Discrepancy in indicating information relevant to countability}

The specifications [singular] or [plural] help learners clarify their perceptions about countability of a noun in their immediate situations, but the combination of the labels [C] or [U] with these specifications may cause confusion. For instance, in LDCEO as well as in OALD7, education is marked as [singular, uncountable] when it means the process of teaching and learning or a particular kind of teaching or training. However, being uncountable already means the word cannot be used grammatically in plural and will only occur in its uninflected form in usage, because "an uncountable noun has only one form, not a separate singular and plural" (OALD7: R42). English learning in Chinese educational contexts strictly observe such an understanding as the concept of countability is a key point examined in English tests at various levels. There- 
fore, such marking seems to be superfluous and may be misunderstood by Chinese learners.

Additionally, the discrepancy between the labels and usage examples indicating the countability feature of a noun tends to confuse Chinese learners. For instance, in LDCEO the word education has been explicitly marked as uncountable when it occurs in senses 1,2 and 3, but the phrase examples get/ receive an education are provided under the first sense. This therefore contradicts the definition on the back of the front cover of MED2 "uncountable nouns that cannot be used with $a$ or an or a number and have no plural". Being uncountable labels it as impermissible in combination with $a / a n$. This matches Chinese learners' experience in English classrooms in China. Faced with such data presentation in dictionaries, Chinese learners may be wondering which rule to follow. Considering the authoritative status of dictionaries in Chinese learning culture, Chinese learners may follow the examples in their immediate situation, but their uncertainty will not be settled.

\subsection{Inefficiency of exemplifications}

Examples have long been considered an effective way to demonstrate syntactic behaviour in context. However, the potential of examples is not fully exploited for demonstrating the information related to nominal countability, especially regarding those nouns with which foreign learners tend to commit errors. For instance, the example from LDCEO, I need more information, is not effective to show that much information instead of many information is appropriate. Similarly, in LDCEO, MDO and OALD7 fish has been marked as countable when it means "an animal living in water which swims", but the listed examples do not assure Chinese learners of the appropriateness of their writing three fish(es).

\subsection{Difficulty of accessibility}

In both printed (e.g. OALD7) and online dictionaries (e.g. MDO), the accessibility to the needed data still demands much effort. In printed dictionaries, users have to carefully scrutinize the heavily-packed entry to locate the needed data. Also, the online dictionary MDO does not show much improvement in this respect, although theoretically there are no space restraints for online dictionaries. The thin font and the crammed data make it hard for users to quickly access the needed data, adding mental pressure to them as well. LDCEO performs the best among these dictionaries, but still remain traditional in directing users to the required data. If users start their search with $a / a n$ information, LDCEO will produce an indifferent comment like "a information has returned no result" rather than direct users to the article information with the correct expression highlighted for easy identification, while MDO directs users to the phrase a mine of information in the article mine instead of a piece of 
information or much information in the article information. Moreover, some nouns whose meanings in singular and plural forms are different from each other are still condensed in the entries of their singular forms, such as glasses (referring to spectacles) in the entry glass, and arms (referring to weapon) in the entry arm. Such presentations tend to prolong the access time.

As can be seen from the above analysis, the present lexicographic practice regarding countability demands much effort from learners in the process of data access and information retrieval. The deficiency in the present lexicographic practice can be attributed to the native dictionary-makers' neglect of the target users' specific needs in a concrete situation (e.g. Chinese learners in English writing), or their overestimation of foreign learners' knowledge of English vocabulary and grammar. In real situations, foreign learners consult dictionaries to retrieve the needed information for their immediate use and have no interest in delimiting linguistic concepts of nominal countability. Dictionaries are expected to actively accommodate their lexicographic needs arising in concrete situations rather than being a repository of knowledge waiting to be exploited. Béjoint (1981: 221) proposes that "foreign students need to be given enough information to help them avoid mistakes, and possibly even to attain ease, elegance and subtlety in their use of the foreign language". But lexicographers should go further by explicitly presenting the necessary information for quick access and easy retrieval by these users in their particular situations.

\section{Suggestions for presenting the required data regarding nominal count- ability}

In view of the deficiency in the present lexicographic practice of presenting nominal countability, and the profile of Chinese learners, the following proposals are made for future lexicographic research and practice in this respect. These suggestions are free from dictionary formats, and adaptations may be needed with regard to the practical aspects when it concerns the different dictionary formats and different dictionary user groups. The example articles are presented after each suggestion for demonstration purposes. In order to highlight the data concerning this study, other lexicographic data in the example articles are omitted on purpose. Some usage examples are taken from dictionaries examined in this study.

\subsection{Presenting information on articles and the plural forms of nouns}

To assist foreign learners in immediate usage situations, the articles $a / a n$ and the, or a dash to indicate no articles, as well as the plural inflection of a noun, such as $-s$ or -es, can be bracketed before the definition part when the noun is marked as countable. If the plural inflection is irregular, the full word form should be presented. (This has been practised in some learner's dictionaries.) It 
is also better to indicate that the uncountable nouns cannot be used with the indefinite articles $a / a n$ or cardinal numbers and that they undergo no formal changes in terms of number. In print dictionaries, the swung dash $(\sim)$ can be used to indicate the headword for reasons of space, while in online dictionaries, it is recommendable to display the full word form to avoid any possible confusion. Such treatment will save foreign learners much effort to consider whether an article is needed or which article should be used as well as the possible plural inflections. On the other hand, it will raise the awareness of foreign (e.g. Chinese) learners regarding the use, when necessary, of articles, cardinal numbers or plural forms. Given the fact that foreign learners may find it difficult to process linguistic metalanguage, this study argues that it is necessary to clearly indicate the articles used before a noun rather than to use grammatical terminologies like "no indefinite articles".

Being limited, this study does not address learners' difficulties with quantifiers used before nouns, but it holds that more explorations should be conducted in this respect. In some of the following articles, however, a few examples with quantifiers will be given, but the use of quantifiers before nouns needs careful consideration. For instance, some nouns, like bread, noodle, and vegetable, cannot be combined with quantifiers with one contextual meaning, but when they assume another contextual meaning, it is possible. When these nouns assume the contextual meaning of variety, they could be combined with articles $a / a n$ or quantifiers two and many. When they refer to the food as a whole such combination is impossible. Example article 3 noodle (below) demonstrates this.

oasis /.../ noun (an oasis, the oasis; plural: oases, the oases) ...

\section{Example article 1}

bread $/$... noun

1. (Use: bread, not: a bread, breads) a type of food made from ...

a piece/loaf of bread

2....

\section{Example article 2}

\subsection{Delineating the usage of nouns that are both countable and uncount- able}

If a noun is countable, having both singular and plural forms, but tends to be used in the plural form, such as noodle, congratulation (when it refers to the words used to congratulate someone), the plural form should be provided either by presenting the inflectional suffix, such as $-s$ or -es, or showing the full word form if there is irregular numeral inflections. (This has been widely prac- 
tised.) Explicit recommendations should be given concerning the circumstances under which the singular or the plural form of a noun is used, instead of vague expressions like "often" and "usually", as it is difficult for foreign learners to decide whether their usage situations can be categorized into the "often" or "usually" cases. The recommendations can be indicated in different ways: stated directly; transmitted through the definition; demonstrated in phrase or sentence examples.

noodle /.../ noun (plural: noodles) ...

When we refer to food, we use noodles.

When we refer to the physical object, we can say a noodle, many noodles.

a bowl of noodles

Chinese food is often served with rice or noodles.

\section{Example article 3}

congratulation $/ \ldots /$ noun $\ldots$

1. When you congratulate someone, you should say congratulations, not congratulation

congratulations on

2. (Use: congratulation; not: eengratulations) the act of congratulating sb a letter of congratulation

\section{Example article 4}

A distinction should be made with explanations or typical examples when a noun is used both as countable and uncountable. There are two possible situations when a noun is marked as countable as well as uncountable. If the countability features of a noun are connected with its meanings in context, such as experience, difficulty, fruit, vegetable, room, etc., the distinction should be illustrated explicitly in definitions, by synonyms or even equivalents (e.g. Chinese equivalents for Chinese learners), when necessary. Moreover, the examples immediately following are expected to help foreign learners decide on the appropriate word form in the relevant syntactic environments. On the other hand, if a noun can be used both as countable and uncountable with the same contextual sense, recommendations or prescriptions are needed, depending on the dominant countability features in the specific contexts. For instance, the noun effort is prominently used as a countable taking both singular and plural forms in contexts when it means "an attempt to do something", despite being marked as both countable and uncountable. Therefore, there is no need to add to foreign learners' uncertainty by indicating this word as having dual identities of countability. 
experience $/ \ldots /$ noun $\ldots$

1. (Use: experience) 经验

She has gained much experience in the computer industry.

2. (Use: experience) ( 生活) 阅历

Experience has taught me that life can be very unfair.

When experience refers to 经验，(生活)阅历, you can only use: experience + singular verb, not: experience, many experiences

3. (a/an + (adj) + experience; plural: experiences) 经历 , 体验 an unforgettable/exciting/enjoyable experience our childhood experiences

Living in Africa was very different from home and quite an experience.

\title{
Example article 5
}

\author{
effort $/ \ldots /$ noun $\ldots$ \\ 1.... \\ 2. (an effort; efforts) an attempt to do something \\ an effort to do something \\ make an/every effort to do something \\ make efforts to do something
}

\section{Example article 6}

\subsection{Demonstrating information about subject-verb agreement}

The difficulty of foreign learners with the subject-verb agreement in connection with nominal countability should be treated carefully, especially when collective nouns are involved. Generally speaking, the problems caused by the understanding of collective nouns can be classified into the following cases: (i) the collective noun takes the singular word form and can be syntactically singular and plural depending on the intended meaning when used in a particular context, such as class, family, team, audience, etc.; (ii) the collective noun takes the singular form but can only be used with a plural meaning and cannot be used together with the indefinite articles $a / a n$ or the singular quantifiers each or every, such as cattle, people, police, etc.; (iii) the collective noun takes a plural form and is syntactically plural, such as clothes, glasses, goods, belongings, credentials, etc., but cannot be preceded by cardinal numbers (e.g. the singular form maintaining the meanings unchanged; (iv) the collective noun has the singular form and is syntactically singular, such as luggage, furniture, equipment, etc., but cannot be used with the indefinite articles a/an or cardinal numbers. However, even the widely-acknowledged dictionary MED2 seems to ignore foreign learners' difficulties with the subject-verb agreement 
caused by their misconception of or uncertainty about the collective nouns. For instance, it is almost impossible for foreign learners to abstract information about the appropriate verb forms following the word cattle either from the label [pl] or the examples diary cattle and a cattle ranch in the article cattle. This study therefore proposes the corresponding treatment of collective nouns as follows: indicating possible articles when necessary, giving explicit usage notes on verb forms, presenting demonstrative examples and providing common error warnings.

cattle /.../ noun (Use: cattle + plural verb, the cattle, not: a cattle, eattles) ...

The cattle are grazing.

Hundreds of cattle are slaughtered every day.

\section{Example article 7}

family /.../ noun (a family; the family, plural: families) ...

Use: family + singular verb when referring to a whole family

My family has always been close.

Use: family + plural verb when referring to family members $(B r E)$

The whole family have colds.

\section{Example article 8}

In addition to collective nouns, there is a category of nouns ending in -s or -es, such as the names for certain diseases (e.g. measles, mumps, arthritis), sciences (e.g. physics, acoustics, economics), games (e.g. marbles, skittles, draughts), and countries (e.g. United States, Netherlands). Despite the seemingly plural endings, these words are used as singular in syntactic environments. The presentation of the data concerning the use of the articles before these words and the subjectverb agreement can follow the above suggestions in accordance with the context in which the word is used. It should take into account that the contextual meaning of these words may influence their syntactic behaviour, for instance, marbles can be counted (e.g. many marbles) when referring to the round objects of the game instead of the game itself. Thus, the presentation of the relevant data is expected to be adapted accordingly.

\subsection{Using examples and error warnings to raise learners' awareness}

Examples should be amply employed to demonstrate the countability features of nouns, especially those words with which foreign learners tend to commit errors, for instance, using articles before words with deceptively plural endings (e.g. news, means) and the following verb forms in relevant syntactic environ- 
ments. Others like advice and information are uncountable and invariable in their base forms, but foreign learners with certain language backgrounds tend to treat them as countables. Examples like The news is good and The police have arrived will be indicative of the syntactic behaviour of these nouns and help learners retrieve the needed information more easily. When necessary, warnings on common errors made by foreign learners can be provided for drawing learners' attention to the appropriate word forms. The error warnings can take different forms depending on the nature of the errors and the profile of the foreign learners. Both the examples indicating the salient countability features of a noun and the highlighted errors should be understood from the perspective of the foreign learners.

advice $/ . . . /$ noun ...

My supervisor gives me some good advice in my research.

His advice on my study is always enlightening.

Error warnings

You can say/write: a piece of advice, two pieces of advice, a lot of advice, not: antone advice, two advices, many advices

\section{Example article 9}

\subsection{Integrating study pages on English grammar}

Integrating study pages on specific grammatical points in learner's dictionaries, such as nominal countability may be helpful for foreign learners to study certain aspects of English grammar systematically in their cognitive learning situation, but not quite relevant to foreign text production activities. In production-oriented situations, fewer learners will consult this information as they aim to abstract specific grammatical information about individual words in their immediate situations (e.g. article use) rather than the grammar in general. Therefore, this study restricts its discussion in this respect. Admittedly, the study pages are necessary if the dictionary is aimed to serve multifunctional purposes, but the point of departure should be its intended users' grammar knowledge and their needs in the particular user situations rather than the linguistic knowledge itself (Andersen 2007: 133).

\subsection{Making an improvement in data accessibility and information retrie- val}

In view of the above analysis, the presentation of the data related to nominal countability is expected to be explicit and salient for the purpose of quick data accessibility and easy information retrieval. Typography can be fully used for easy data identification. For instance, the bracketed data shaded in the above 
example articles can be highlighted in colour in real reference works. The colour font is abandoned in the example articles because it cannot be rendered here. Online dictionaries should exploit the full potential offered by the development of technology, especially regarding search and access routes. For instance, the search starting with a misconception of nominal countability, such as an advice, can direct foreign learners to locate the appropriate expressions in the related articles. Compared with the online dictionaries, the printed dictionaries are restrained in space and search routes. But as shown above, it is possible for printed dictionaries to present the necessary data clearly giving entry status to those nouns whose meaning in their plural forms differs greatly from that of their singular forms and place them adjacent to each other instead of strictly observing the alphabetical order, such as glass/glasses, good/goods, arm/ arms, custom/customs, etc. According to the profile of the learners, the access routes to the needed data can also be various.

The usage notes and error warnings in the box are mainly written in English for the benefit of the readers of this article. In real situations, foreign learners' native language may be considered depending on the quality of the concerned data and the profile of the dictionary users. This study is intended to optimize lexicographic solutions to foreign learners' problems regarding nominal countability, but the realization of these solutions depends on the real situations. This study takes into account that more comprehensive future research is needed, for instance the presentation of information concerning quantifiers. Neologisms should also receive their due attention, as they are concurrent with social development. Many new words have been coined to describe the dynamic world of the information age with some words passing beyond their traditional sense, for instance blog is replacing diary, and mail is referring to email. Thus, the countability features of some nouns need to be reconsidered in lexicographic practice.

\section{Conclusion}

This study shows that the current lexicographic practice regarding nominal countability does not effectively help Chinese learners out of their difficulties with nominal countability in English writing. Foreign learners' lack of reference skills or unfamiliarity with dictionaries cannot in this respect justify the deficiency in dictionaries. Admittedly, the dictionaries discussed target ESL/EFL learners generally rather than Chinese learners specifically, which could partially account for the deficiency in the lexicographic treatment of nominal countability as shown in this study. However, this fact just accentuates the need to create learner's dictionaries that are actively involved in foreign language learning by giving serious consideration to the specific group of foreign learners and the particular situations that prompt their dictionary consultations. It is essential that the presentation of the lexicographic data be understood from the target dictionary users' perspective. Different lexicographic data 
should be integrated and balanced to achieve the pedagogical function intended by learner's dictionaries.

It is unrealistic to expect foreign learners in the immediate situation to analyze and synthesize linguistic data covered in dictionaries as it demands them to have full knowledge about the vocabulary and grammar in the target language. It is the lexicographers' role to identify the real lexicographic needs of the target users in lexicographically-related situations, utilize linguistic expertise to make analytic and synthetic work on the corresponding data, and present the necessary data for quick data access and easy information retrieval from the target users' perspective. Upon minimizing dictionary users' frustrations during their look-ups, it is still meaningful to consider Rundell's (1999: 48) proposal a decade ago: "[a] more realistic strategy is to aim for dictionaries whose structure is so transparent that students do not need to learn how to use them, and whose content is presented in such straightforward terms that users will have no difficulty in grasping it."

\section{References}

Andersen, B. 2007. Dictionary Grammars. Hermes, Journal of Language and Communication Studies 38: 119-136.

Béjoint, H. 1981. The Foreign Student's Use of Monolingual English Dictionaries: A Study of Language Needs and Reference Skills. Applied Linguistics 2(3): 207-222.

Chang, J. 1987. Chinese Speakers. Swan, M. and B. Smith (Eds.). Learner English: 224-237. Cambridge: Cambridge University Press.

Chuang, F.Y. 2005. Article Misuse: A Neglected Problem in Chinese EAP Student Writing. M. Singhal and J. Liontas (Eds.). 2005. Proceedings of the Second International Online Conference on Second and Foreign Language Teaching and Research: Initiative, Innovation, and Inspiration: 25-33. The Reading Matrix Inc., United States.

Cowie, A.P. 1999. English Dictionaries for Foreign Learners: A History. Oxford: Clarendon Press.

Gui, S.C. and H.Z. Yang. 2003. Chinese Learner English Corpus. Shanghai: Shanghai Foreign Language Education Press.

Hausmann, F.J. and A. Gorbahn. 1989. COBUILD and LDOCE II: A Comparative Review. International Journal of Lexicography 2(1): 44-56.

Hornby, A.S. 1965. Some Problems of Lexicography. English Language Teaching 19(3): 104-110.

Longman Dictionary of Contemporary English Online (LDCEO). http://www.ldoceonline.com/

Macmillan Dictionary Online (MDO). http://www.macmillandictionary.com/

Master, P. 1997. The English Article System: Acquisition, Function, and Pedagogy. System 25: 215232.

Master, P. 2002. Information Structure and English Article Pedagogy. System 30: 331-348.

Miller J. 2006. An Investigation into the Effect of English Learner's Dictionaries on International Students' Acquisition of the English Article System. International Education Journal 7(4): 435445.

Milton, J. 2001. Elements of a Written Interlanguage: A Computational and Corpus-based Study of Institutional Influences on the Acquisition of English by Hong Kong Chinese Students. 
James, G. (Ed.). 2001. Research Reports, Volume Two. Hong Kong: Language Centre, Hong Kong University of Science and Technology.

Palmer, H.E. 1938. A Grammar of English Words. London: Longmans, Green \& Co.

Robertson, D. 2000. Variability in the Use of the English Article System by Chinese Learners of English. Second Language Research 16(2): 135-172.

Rundell, M. 1999. Dictionary Use in Production. International Journal of Lexicography 12(1): 35-53.

Rundell, M. (Ed.). 20052. Macmillan English Dictionary. New York: Palgrave Macmillan.

Sinclair, J. 1991. Corpus, Concordance, Collocation. Oxford: Oxford University Press.

Svensson, P. 1998. Number and Countability in English Nouns. Uppsala: Swedish Science Press.

Swan, M. and B. Smith. 1987. Learner English. Cambridge: Cambridge University Press.

Tang, E.Y. 2006. Linguistic Environment as a Determinant of English Countability. http://www. paaljapan.org/resources/proceedings/PAAL11/pdfs/22.pdf: 266-280. [November 4, 2009.]

Tarp, S. 2008. Lexicography in the Borderland between Knowledge and Non-knowledge. General Lexicographical Theory with Particular Focus on Learner's Lexicography. Tübingen: Max Niemeyer.

Wehmeier, S. (Ed.). 2005. Oxford Advanced Learner's Dictionary of Current English. Seventh Edition. London: Oxford University Press. 